\title{
Placental pathology in intra: uterine foetal deaths
}

\section{Nanda J. Patil ${ }^{1}$, Dhirajkumar Buddhiram Shukla ${ }^{2}$, Shrutika Dhawan ${ }^{3}$}

\author{
${ }^{1}$ Professor, Department of Pathology, Krishna Institute of Medical Sciences University, Karad- 415110, Maharashtra, \\ India \\ ${ }^{2}$ Assistant Professor, Department of Pathology, Krishna Institute of Medical Sciences University, Karad- 415110, \\ Maharashtra, India \\ ${ }^{3}$ Tutor, Department of Pathology, Krishna Institute of Medical Sciences University, Karad- 415110, Maharashtra, India
}

Received: 05 May 2016

Accepted: 02 June 2016

\section{*Correspondence:}

Dr. Dhirajkumar Buddhiram Shukla,

E-mail: drshukla.patho@gmail.com

Copyright: ( ) the author(s), publisher and licensee Medip Academy. This is an open-access article distributed under the terms of the Creative Commons Attribution Non-Commercial License, which permits unrestricted non-commercial use, distribution, and reproduction in any medium, provided the original work is properly cited.

\begin{abstract}
Background: Intra-uterine foetal death (IUFD) is an agonizing and often unpredictable event. Most of the times, placental lesions are direct cause of perinatal morbidity and has an impact on management of further pregnancies. The objective of this study was to diagnose lesions of placenta in intra-uterine foetal deaths and to evaluate placental causes of intra-uterine foetal deaths.

Methods: A retrospective study of 65 cases of IUFD within a period of 5 years from January 2007 to December 2011 was carried out in our institute.

Results: Amongst 65 cases of IUFD, in 50 cases (77\%) the cause of death was directly related to placenta while in 2 cases $(3 \%)$ the cause was related to foetal abnormality. In 9 cases $(13.8 \%)$ lesions of placenta were not directly leading to IUFD while unexplained causes were noted in 4 cases $(6 \%)$.

Conclusions: Placental examination plays a vital role in evaluating cause of IUFD.
\end{abstract}

Keywords: Placenta, IUFD

\section{INTRODUCTION}

Intra-uterine foetal death (IUFD) is defined as death of foetus of $>24$ weeks of gestation and/ or weighing $>500$ gms. ${ }^{1}$ Placenta is the most accessible and readily evaluable specimen, examination of which provides a record of pregnancy in which the cumulative effects of pregnancy-related events and changes reflecting the intrauterine environment can be scrutinized. The present study was carried out in our tertiary care hospital to evaluate the placental causes of IUFD.

The objective of this study was to diagnose lesions of placenta in intra-uterine foetal deaths. And to correlate the findings with clinical diagnosis and relevant investigations. And to evaluate placental causes of intrauterine foetal deaths.

\section{METHODS}

A retrospective study of 65 cases of IUFD within a period of 5 years from January 2007 to December 2011 was carried out in our institute with the consent of ethical committee of our institute.

Each case was studied in detail taking in account clinical presentation, ANC records, past history, placental examination and other relevant investigations. The histopathological reports and slides were reviewed in detail. 


\section{RESULTS}

- Total 65 cases of IUFD were obtained within a period of 5 years from January 2007 to December 2011.

- Majority (94\%) cases were in 21-30 years of age group; the age range being 17- 38 years.

- Primigravidas $(53.8 \%)$ were slightly more in number.

- Preterm deliveries (54\%) outnumbered the full term $(43 \%)$ and post-dated $(3 \%)$.

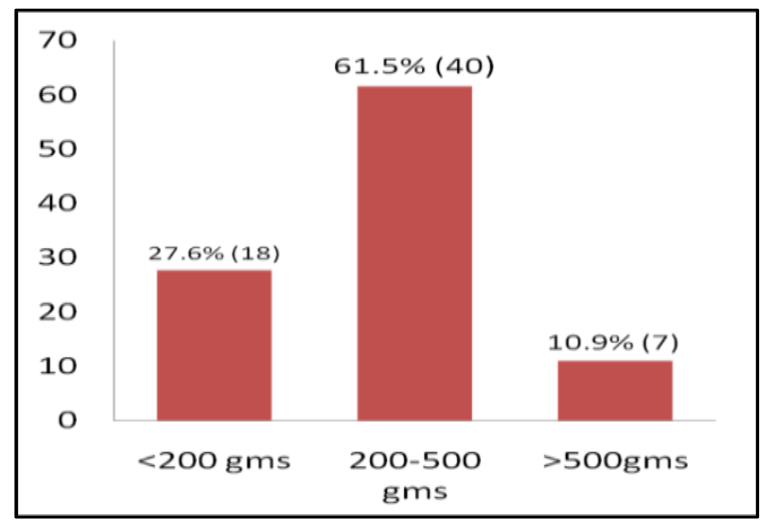

Figure 1: Placental weight.

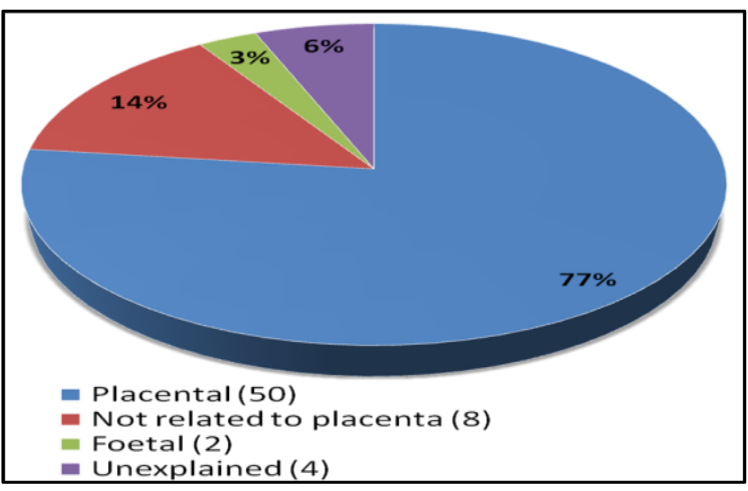

Figure 2: Causes of IUFD.

- In <200 gms, placental lesion was direct cause of IUFD. Majority of them were chorio-amnionitis $(55.5 \%)$ followed by utero-placental insufficiency (UPI) $22.2 \%$.

- Placental causes were chorioamnionitis, UPI and twin-transfusion syndrome.

- Foetal causes included congenital anomalies (anencephaly; two chambered heart) and $\mathrm{Rh}$ incompitability.

- Causes not directly related to placenta showed chorangiosis and amnion nodosum.

\section{Placental lesions}

Out of the 50 cases with placental causes of IUFD, chorioamnionitis (CA) and utero-placental insufficiency
(UPI) were leading cause of IUFD in our study (Figure 3).

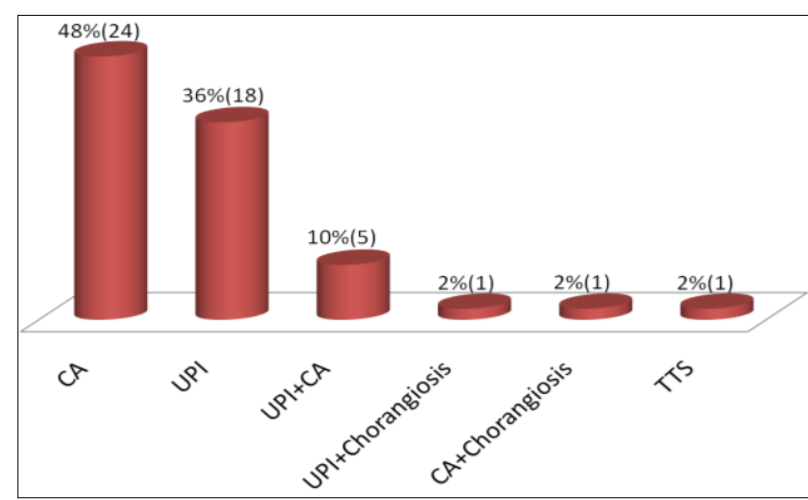

Figure 3: Contributory lesions of placenta in IUFD.

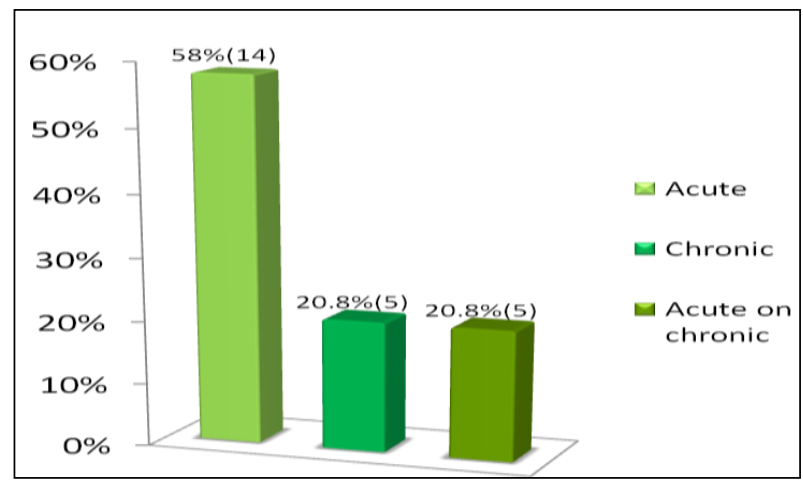

Figure 4: Distribution of cases of chorioamnionitis.

\section{Chorioamnionitis}

Chorioamnionitis was present in 24 cases $(36.9 \%)$ either in acute, chronic or acute on chronic form as shown in Figure 4. Severe anemia was noted in 3 cases. Two cases with chronic chorioamnionitis had past history of spontaneous abortions amongst which only 1 case was seropositive for TORCH infection. However, characteristic inclusion bodies were not found in histopathology slide examination (Figure 5).

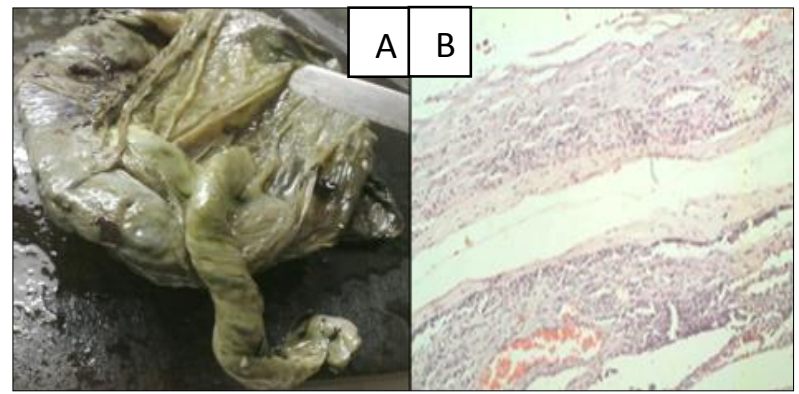

Figure 5: (A) Gross photograph of placenta showing thick whitish membranes in chorioaminonitis; (B) photomicrograph showing acute chorioaminonitis $(H$ and $\mathrm{E}, 100 \mathrm{x}$ ). 


\section{Pregnancy-induced hypertension (PIH)}

We observed 14 cases of PIH (21.53\%). In 7 cases $(50 \%)$, weight of placenta was significantly low. Uteroplacental insufficiency was the main placental pathology seen in PIH (Figure 6 and 7).

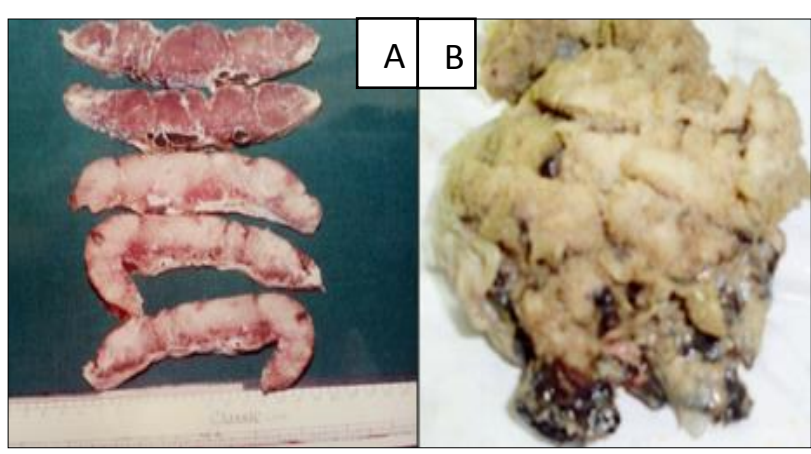

Figure 6: (A) Gross photograph of fresh infarct in PIH; (B) photomicrograph of old infract in PIH.

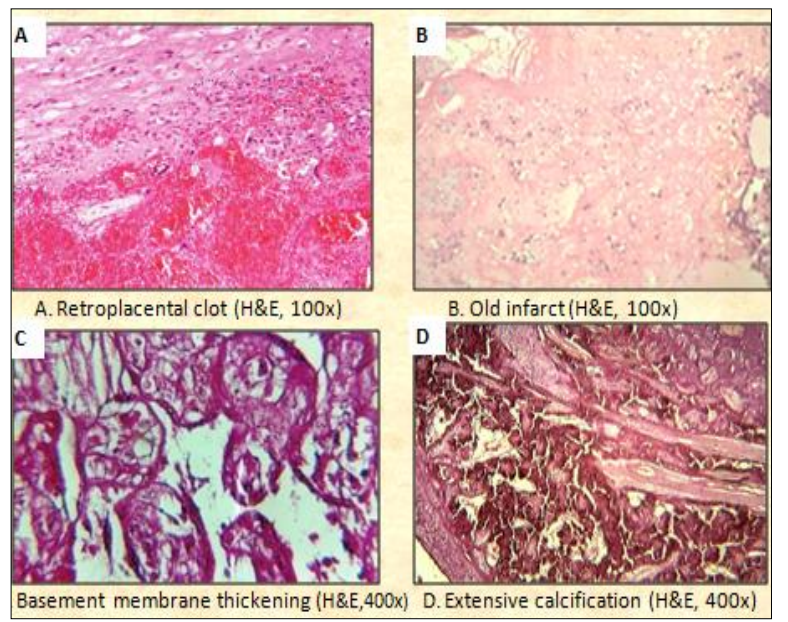

Figure 7: Photomicrograph of various changes in cases of PIH. (A) Retroplacental clot (H and E, 100x);

(B) old infarct (H and E, 100x); (C) basement membrane thickening (H and $\mathrm{E}, 400 \mathrm{x})$; (D) extensive calcification ( $\mathrm{H}$ and $\mathrm{E}, \mathbf{4 0 0 x})$.

\section{Maternal anemia}

Anemia was present in $13.8 \%$ (9) cases which was moderate grade in majority $(55.5 \%)$. Amongst 3 cases of severe anemia, 2 cases revealed significantly low placental weight.

\section{Congenital anomalies}

Only $7.7 \%$ (5) cases had congenital anomalies which included anencephaly, two chambered heart and meningocele. In 2 cases, it was direct cause of IUFD while in others placental pathology played contributory role.

\section{DISCUSSION}

Intra-uterine fetal death is more common in the age group of 21-30 years and primigravida patients are more prone. The other studies also revealed similar observations. ${ }^{1,2}$

The cause of IUFD can be maternal, foetal or placental. Several studies have shown placental pathology as a major contributor to IUFD, hence stressing the importance of its examination. ${ }^{3-5}$ Kortweg et al, included placental histopathology in the classification for the causes of perinatal deaths. ${ }^{6}$ In present study, placental pathology was direct cause in $77 \%$ of IUFDs.

Maternal infection, PIH and anemia are the majority (72.2\%) of causes of IUFD which can be completely treated avoiding the further complication of IUFD in next pregnancy. In women with clinical risk factors like PIH and anemia, placental pathology reveals low placental weight and utero-placental insufficiency. ${ }^{2,7}$ In a study by Tolockiene et al, chorioamnionitis was noted in $82 \%$ of stillbirth but bacteria was found only in $50 \%$ of them. Similarly, in present study, only 1 case of chorioamnionitis showed seropositivity for TORCH infections. $^{8}$

Twin transfusion syndrome can be diagnosed earlier with ultrasonography and IUFD can be prevented by effective management during pregnancy which includes endoscopic laser surgery and amniocentesis. ${ }^{9}$

Foetal causes in our study contributed only to $3 \%$ of IUFD. Congenital anomalies were noted in $7.7 \%$. Similar results were seen in study by Choudhary et al and Kortweg et al. ${ }^{1,4}$

IUFD is a tragic event for parents and a great cause of stress for caregivers. Identification of cause of IUFD will be helpful in counseling and consoling the grieving parents and alley their fear regarding future pregnancy.

\section{CONCLUSION}

- Pathological examination of placenta plays a vital role in investigating causes of IUFD.

- Clinical history and investigations of mother and baby play an important role in making histopathological diagnosis of placental lesions.

- Placental examination assists in timely management of mother and foetus which can improve outcome of further pregnancies; hence it should be routine component of obstetric and neonatal care.

Funding: No funding sources

Conflict of interest: None declared

Ethical approval: The study was approved by the Institutional Ethics Committee 


\section{REFERENCES}

1. Choudhary A, Gupta V. Epidemiology of intrauterine fetal deaths: a study in tertiary referral centre in Uttarakhand. IOSR-JDMS. 2014;13(3):3-6.

2. Ujwala $\mathrm{CH}$, Guruvare $\mathrm{S}$, Bhat $\mathrm{S}$, Rai L, Rao S. Evaluation of placenta in fetal demise and fetal growth restriction. J Clin Diagn Res. 2013;7(11):2530-3.

3. Kidron D, Bernheim J, Aviram R. Placental findings contributing to fetal death, a study of 120 stillbirths between 23 and 40 weeks gestation. Placenta. 2009;30(8):700-4.

4. Korteweg FJ, Erwich JHM, Holm JP, Ravise JM, Meer J, Veeger JGM, et al. Diverse placental pathologies as the main causes of fetal death. Obstet Gynecol. 2009;114(4):809-17.
5. Hayati AR, Khong TY, Zainul R. The usefulness of limited placental sampling in stillbirths. Malaysian J Pathol. 1998;20(2):99-102.

6. Korteweg FJ, Gordijin SJ, Timmer A. The Tulip classification of perinatal mortality: introduction and multidisciplinary inter-rated agreement. BJOG 2006;113:393-401.

7. Joshi VV. Handbook of placental pathology. New York Igaku-Shoin Medical Publications; 1994:81-92.

8. Tolockiene E, Morsing E, Holst E, Herbst A, Ljungh A, Svenningsen $\mathrm{N}$, et al. Intrauterine infection may be a major cause of stillbirth in Sweden. Acta Obstet Gynecol Scand. 2001;80(6):511-8.

9. Patil N, Khedkar J, Desai S. Placental pathology in twin transfusion syndrome-a case report. Int J Health Sci Res. 2012;2(6):123-5.

Cite this article as: Patil NJ, Shukla DB, Dhawan S. Placental pathology in intra: uterine foetal deaths. Int J Reprod Contracept Obstet Gynecol 2016;5:2250-3. 